\title{
CARACTERIZAÇÃO MORFOLÓGICA DO DELTA DO RIO DOCE (ES) COM BASE EM ANÁLISE MULTISSENSOR
}

\section{MORPHOLOGICAL CHARACTERIZATION OF THE DOCE RIVER DELTA (ES) BASED ON MULTISENSOR ANALYSIS}

\author{
Silvia Palotti Polizel \\ Divisão de Sensoriamento Remoto, Instituto Nacional de Pesquisas Espaciais. \\ Av. dos Astronautas, 1758 - Jardim da Granja - São José dos Campos/SP - Cep: 12.245-970, Brasil. \\ E-mail: sppolizel@gmail.com
}

Dilce de Fátima Rossetti

Divisão de Sensoriamento Remoto, Instituto Nacional de Pesquisas Espaciais Av. dos Astronautas, 1758 - Jardim da Granja-São José dos Campos/SP - Cep: 12.245-970, Brasil.

E-mail:rossetti@dsr.inpe.br

\section{Informações sobre o Artigo}

Data de Recebimento:

04/04/2014

Data de Aprovação:

$30 / 06 / 2014$

\section{Palavras-chave:}

Mapeamento geomorfológico; delta do rio Doce;

sensoriamento remoto.

\section{Keywords:}

Geomorphological mapping;

Doce River delta; remote sensing.

\section{Resumo:}

A costa leste brasileira apresenta uma sucessão de sistemas deltaicos, sendo o delta do rio Doce, localizado no Estado do Espírito Santo, um dos mais expressivos. A progradação principal deste delta, de geometria cuspidada típica de deltas de onda, tem sido atribuída à queda do nível do mar que se seguiu à transgressão holocênica média. Análises preliminares de novos produtos de sensoriamento remoto disponibilizados nesses últimos anos mostraram o potencial de aprimoramento do mapa geomorfológico desse delta, que pode contribuir para a melhor reconstituição paleoambiental e evolução desse sistema deposicional. Assim, este trabalho teve por objetivo fornecer um mapa geomorfológico detalhado para a planície costeira do rio Doce com base em dados multissensores integrando Modelo Digital de Elevação (MDE) do Shuttle Radar Topography Mission (SRTM), Phased Array type L-band Synthetic Aperture Radar (PALSAR) do Advanced Land Observing Satellite (ALOS), imagens TM/Landsat, além de imagens óticas de alta resolução extraídas do Google Earth ${ }^{\mathrm{TM}}$. O mapeamento geomorfológico feito por interpretação visual resultou no estabelecimento de seis classes principais, designadas de: 1) drenagem atual; 2) cordão litorâneo/spit; 3) paleocanal; 4) planície interdistributária; 5) flúvio-estuarino/lagunar/marinho raso; e 6) terraço fluvial. De maneira geral, o emprego combinado dos produtos de sensoriamento produziu resultados satisfatórios para a separação dessas classes. O MDE-SRTM contribuiu para a identificação somente da classe paleocanais. As imagens PALSAR foram úteis na identificação das classes cordão litorâneo/spit, paleocanal, flúvio-estuarino/lagunar/marinho raso e terraço fluvial. As imagens $\mathrm{TM} /$ Landsat possibilitaram o reconhecimento das classes drenagem atual, cordão litorâneo/spit, planície interdistributária e flúvio-estuarino/lagunar/marinho raso. 
O mapa geomorfológico contribuiu na caracterização mais adequada dos vários subambientes do delta do rio Doce, consequentemente auxiliando na reconstrução de sua dinâmica sedimentar. Assim, sustenta-se que a evolução desse delta se processou de maneira episódica, com oscilações entre fases progradacionais, que resultaram na formação dos cordões litorâneos/spits, e fases transgressivas, que resultaram nos depósitos flúvio-estuarinos/lagunares/ marinho rasos. Além disto, diferentemente de outros deltas de onda formados ao longo da costa brasileira, o delta do rio Doce foi alimentado por canal principal instável, o que gerou uma sucessão de paleocanais em sua planície costeira central. Como consequência dessa dinâmica, houve a formação de um volume significativo de depósitos de planície interdistributária no entorno dos canais, que contribuíram conjuntamente para a destruição dos cordões litorâneos/spits em grande parte do delta. Ilhas desses depósitos em meio a depósitos de planície interdistributária documentam que, no passado, os cordões litorâneos/spits ocorriam em toda a extensão da planície deltaica, tendo sido formados desde as fases iniciais do processo de progradação. Esses dados não são, portanto, condizentes com modelo vigente de delta lagunar nos estágios iniciais de progradação desse sistema deposicional.

\begin{abstract}
:
Brazil's eastern coast has a succession of deltaic systems, with the Doce River delta, located in the State of Espírito Santo, being one of the most expressive. The main progradation of this delta, which has a cuspate geometry typical of wave-dominated deltas, has been attributed to a relative sea-level fall that followed the middle Holocene transgression. Preliminary analyses of new remote sensing products available in recent years have shown the potential to improve the geomorphological map of this delta, which can contribute to better reconstruct the paleoenvironment and the evolution of this depositional system. Thus, this study aimed to provide a detailed geomorphological map of the coastal plain of the Doce River based on multisensor data integrating Digital Elevation Model (DEM) from the Shuttle Radar Topography Mission (SRTM), Phased Array type L -band Synthetic Aperture Radar (PALSAR) of the Advanced Land Observing Satellite (ALOS), TM/Landsat images, and high-resolution optical images derived from Google Earth ${ }^{\mathrm{TM}}$. The geomorphological mapping made by visual interpretation resulted in the establishment of six main classes, designated as: 1) modern drainage; 2) beach ridge/spit; 3) paleochannel; 4) interdistributary plain; 5) fluvio-estuarine/lagunar/shallow marine; and 6) fluvial terrace. In general, the combined application the remote sensing data produced satisfactory results for this classification. The DEM-SRTM helped identify only the paleochannel class. The PALSAR images were useful in identifying classes of beach ridge/spit, paleochannel, fluvio-estuarino/lagunar/shallow marine and fluvial terrace. The TM/Landsat images allowed the recognition of the classes modern drainage, beach ridge/spit, interdistributary plain and fluvio-estuarino/lagunar/shallow marine. The geomorphological map contributed to a more precise characterization of the several subenvironments of the Doce River delta, thus helping the reconstruction of its sedimentary dynamics. Thus, it is argued that the evolution of this delta occurred episodically, with oscillations between progradational phases that resulted in the formation of coastal beach ridges/spits, and transgressive phases that resulted in fluvio-estuarine/lagunar/shallow marine deposits. Moreover, unlike other wave-dominated deltas formed along the Brazilian coast, the Doce River delta was fed by a highly unstable channel, which generated a succession of palaeochannels in the central coastal plain. As a result of this dynamic, there was the formation of a significant amount of interdistributary plain deposits surrounding the channels, which together contributed to the destruction of beach ridges/spits in great part of the delta. Islands of these deposits in the middle of interdistributary plain deposits attest the development of beach ridges/spits throughout the length of the deltaic plain, implying in their formation since the initial stages of delta progradation. These data are, therefore, not consistent with the current model of lagoonal delta in the early stages of development of progradation of this depositional system.
\end{abstract}

\section{Introdução}

Áreas de progradação com formação de sistemas deltaicos nas desembocaduras dos grandes rios da costa leste do Brasil têm sido objeto de pesquisa crescente nos últimos anos, sendo que dentre os deltas mais estudados destacam-se os dos rios Jequitinhonha (BA), Paraíba do Sul (RJ), São Francisco (PE) e Doce (ES) (e.g., DOMINGUEZ et al., 1981, 1983; SUGUIO et 
al., 1982; MARTIN et al., 1984, 1996; DOMINGUEZ, 1987; BITTENCOURT et al., 2007).

O delta do rio Doce, localizado no Estado do Espírito Santo, é uma das morfologias mais expressivas do litoral brasileiro, excedendo $2.500 \mathrm{~km}^{2}$ de área em sua parte subaérea. Este delta tem largura máxima de $40 \mathrm{~km}$ na direção E-W e comprimento máximo de 150 km na direção N-S. Ele representa um delta em cúspide, dominado por ondas suficientemente fortes para transportar sedimentos depositados na desembocadura do rio principal, i.e., do rio Doce. Esse sistema deposicional foi interpretado como tendo sido desenvolvido nos últimos milhares de anos sobre depósitos miocênicos da Formação Barreiras (SUGUIO et al., 1981, 1982; DOMINGUEZ, 1987; DOMINGUEZ et al., 1987; MARTIN et al., 1996). Para alguns desses autores (i.e., DOMINGUEZ et al., 1981; SUGUIO et al., 1982), o delta do rio Doce foi desenvolvido ao longo do litoral brasileiro em função do rebaixamento do nível do mar que se seguiu à transgressão holocênica, quando teria havido a formação da maioria de seus cordões litorâneos. Esses autores propuseram, ainda, a formação inicial de uma laguna, onde o delta do rio Doce teria inicialmente progradado, a qual pode ter se desenvolvido desde o máximo da Penúltima Transgressão (i.e., 120.000 anos BP).

Uma parte importante para o avanço dos estudos de reconstituição paleoambiental do delta do rio Doce é o aprimoramento de seu mapeamento geomorfológico. Os mapas disponíveis foram elaborados com base em estudos regionais derivados de fotografias aéreas, integrados a dados sedimentológicos e cronológicos de natureza pontual (SUGUIO et al., 1981, 1982; DOMINGUEZ, 1987; DOMINGUEZ et al., 1987; MARTIN et al., 1996). Análises preliminares de novos produtos de sensoriamento remoto disponibilizados nesses últimos anos mostraram o potencial de aprimoramento do mapa geomorfológico desse delta. A análise de tais produtos pode resultar em informações relevantes para a melhor caracterização dos diversos subambientes desse sistema deltaico. Esta abordagem pode contribuir para o aprimoramento da reconstituição dos vários estágios de progradação desse delta ao longo do tempo.

Dentre os novos produtos de sensoriamento remoto de potencial para aprimorar o mapeamento geomorfológico do delta do rio Doce ressalta-se as imagens de radar do sensor Phased Array type L-band Synthetic
Aperture (PALSAR) do Advanced Land Observing Satellite (ALOS), imagens TM/Landsat, o Modelo Digital de Elevação (MDE) derivado da tecnologia de Radar Interferométrico de Abertura Sintética (InSAR) adquirido pela Shuttle Radar Topography Mission (SRTM) e imagens óticas de alta resolução do Google Earth $^{\mathrm{TM}}$. O uso integrado desses produtos tem auxiliado o mapeamento geomorfológico detalhado em outras áreas costeiras do território nacional (p.e., RESTREPO; LÓPEZ, 2008; SOUZA FILHO; PARADELLA, 2003; TEIXEIRA; SOUZA FILHO, 2009). Esse tipo de abordagem, aplicada ao delta do rio Doce, pode resultar em um mapa geomorfológico mais detalhado que o disponível até o momento, o qual pode contribuir para a caracterização mais precisa desse sistema deposicional e, consequentemente, melhor entendimento de sua gênese e evolução durante o Quaternário.

O objetivo desse trabalho é fornecer um mapa geomorfológico mais detalhado para a planície costeira do rio Doce utilizando dados multissensores a partir da integração do PALSAR/ALOS, imagens TM/Landsat, MDE-SRTM e imagens óticas de alta resolução. Com isso, espera-se contribuir para a caracterização mais adequada dos vários subambientes desse sistema deltaico e, consequentemente, auxiliar na reconstrução de sua evolução durante o final do Quaternário.

\section{Área de estudo}

O delta do rio Doce localiza-se no Estado do Espírito Santo, entre $18^{\circ} 30^{\prime}$ e $20^{\circ} 00^{\prime}$ de latitude sul, onde se estende sobre os municípios de Conceição da Barra, São Mateus, Jaguaré, Linhares e Aracruz (Figura 1). Esse delta, que ocupa uma área de aproximadamente $2.500 \mathrm{~km}^{2}$, ocorre em uma região caracterizada por clima tropical quente e úmido, com chuvas de verão e invernos secos (tipo climático Aw de KÖPPEN, 1948). Os ventos dominantes são de nordeste e sudeste (SUGUIO et al.,1982).

Geologicamente, o delta do rio Doce insere-se na bacia sedimentar do Espírito Santo-Mucuri (Figura 2). Essa bacia possui área emersa de $18.000 \mathrm{~km}^{2}$ e submersa de $200.000 \mathrm{~km}^{2}$. É limitada a norte pelo complexo vulcânico Abrolhos e a sul pelo arco de Vitória, tendo evoluído sobre um complexo de terrenos ígneos e metamórficos pré-cambrianos (MILANI et al., 2001; MOHRIAK, 2003). O preenchimento sedimentar sin- 

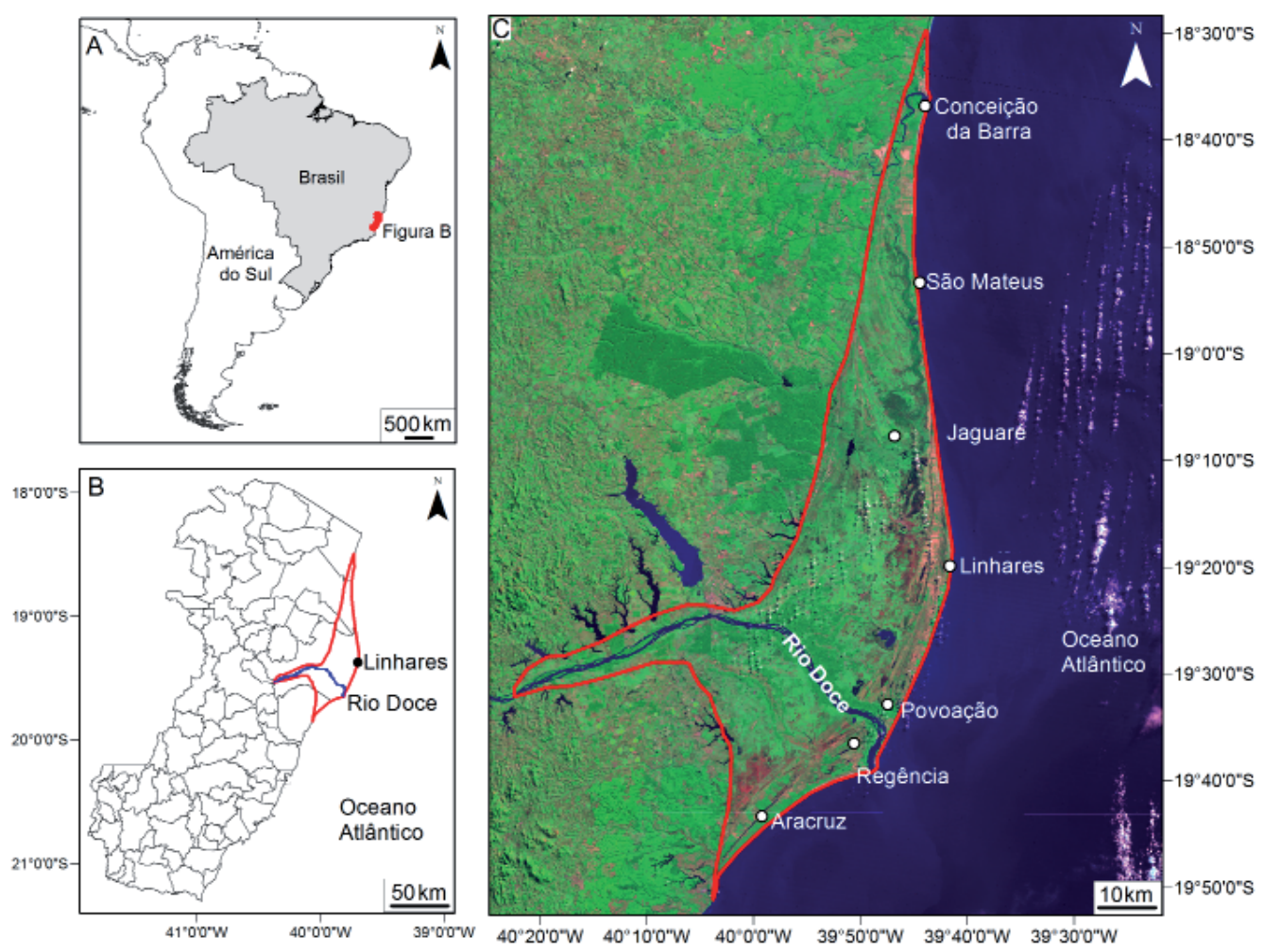

Figura 1 - A - B) Localização do delta do rio Doce no Estado do Espírito Santo. C) Delta do rio Doce visto sobre mosaico de imagens TM/ Landsat com composição R4 G7 B2 (linha vermelha em B e C indica os limites do delta).

rifte da Bacia do Espírito Santo-Mucuri é representado pela Formação Cricaré, de idade Neocomiano/Aptiano e espessura estimada em 5.000 m (MILANI et al., 2001). Sobre esta unidade ocorre a Formação Mariricu, do Neoaptiano. A fase marinha aberta dessa bacia é representada pelo Grupo Barra Nova, de idade albiana, e pelo Grupo Espírito Santo, do Cenomaniano ao Recente. Este último grupo inclui a Formação Barreiras, do Mioceno, e depósitos quaternários do delta do rio Doce. Sedimentos arenosos e argilosos compõem a planície costeira representativa desse delta (IBGE, 1987).

\section{Materiais e métodos}

A base de dados deste estudo incluiu imagens do sensor PALSAR/ALOS, imagens multiespectrais TM/ Landsat, MDE-SRTM refinado para $30 \mathrm{~m}$ disponível no Banco de Dados Geomorfométricos do Brasil - TOPODATA (VALERIANO et al., 2006; VALERIANO; ROSSETTI, 2010), e imagens de alta resolução disponíveis no Google Earth ${ }^{\mathrm{TM}}$.
O ALOS é um satélite de sensoriamento remoto de alta resolução global desenvolvido pela JAXA (Japan Aerospace Exploration Agency) e pelo JAROS (Japan Resources Observation System Organization), que esteve em operação entre 2006 e 2011. Dentre os instrumentos imageadores a bordo desse satélite está o PALSAR, um radar de abertura sintética (SAR) que opera na frequência da banda L, com resolução espacial entre 10 e $100 \mathrm{~m}$, com geração de imagens nas polarizações HH, VV, HV e VH. Esse sensor possui quatro modos de observação: Fine Beam Single Polarization (FBS), Fine Beam Dual Polarization (FBD), Polarimetric mode (POL) e ScanSAR (ROSENQVIST et al., 2004). Operacionalmente, os modos FBS e FBD funcionam com ângulo de incidência de $34,3^{\circ}$, sendo o primeiro com polarização $\mathrm{HH}$ e o segundo com a combinação das polarizações HH/HV (JAXA, 2007; SHIMADA et al., 2009). O conjunto de imagens PALSAR utilizado neste trabalho foi adquirido via Alaska Satellite Facility (ASF). Este consta de quatro imagens PALSAR do período seco, que abrangem praticamente 


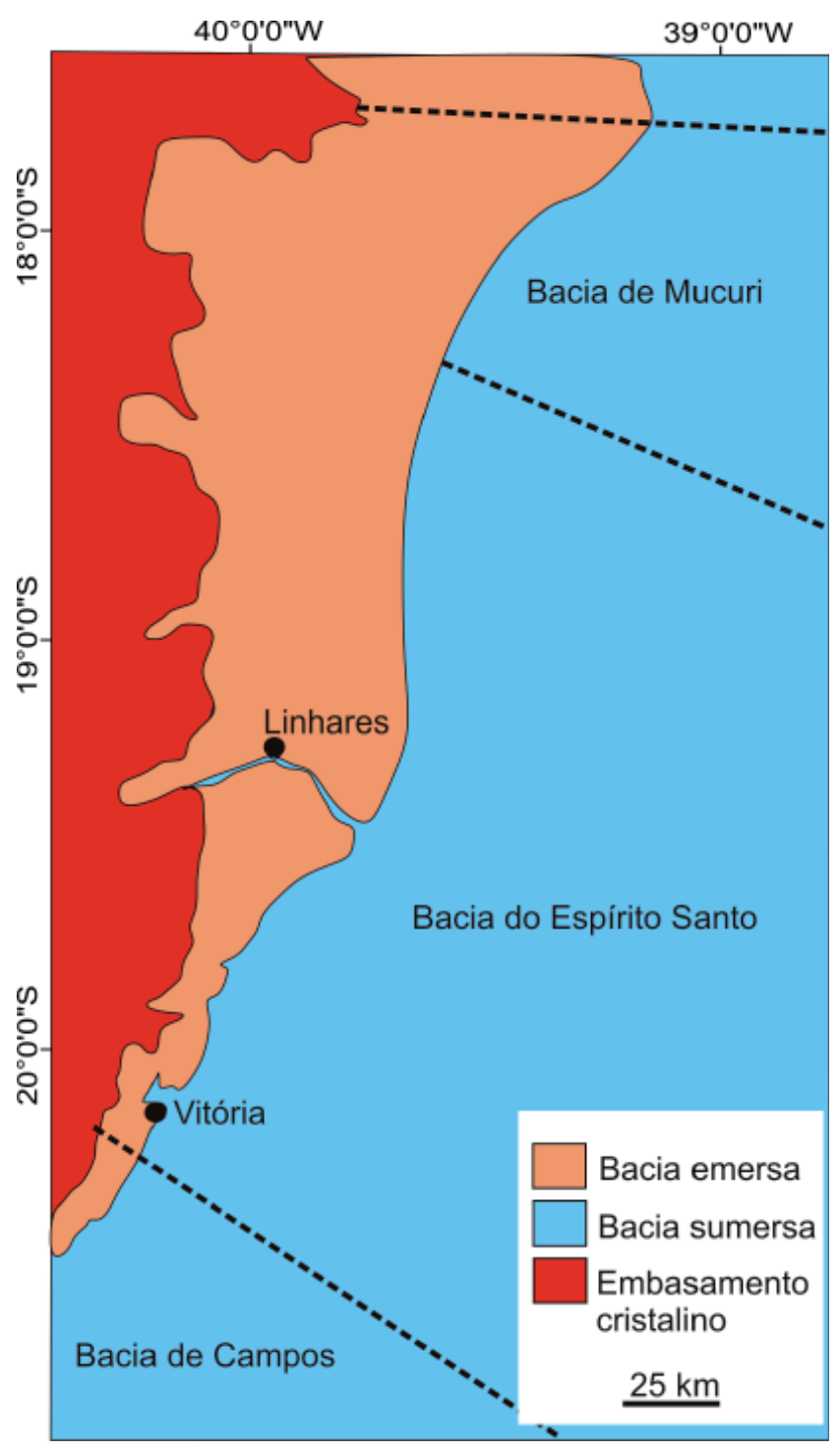

Figura 2 - Bacia sedimentar do Espírito Santo-Mucuri, litoral do Estado do Espírito Santo, ilustrando sua porção emersa e submersa. Fonte: Adaptado de Agência Nacional do Petróleo, Gás Natural e Biocombustiveis (ANP) (2014).

toda a área de estudo. As cenas, datadas de Agosto de 2007, foram adquiridas em órbita ascendente, modo FDB e polarizações HH e HV. Essas imagens já são georreferenciadas, ortorretificadas e processadas no nível 1.5. O único pré-processamento adicional realizado foi a utilização de filtros adaptativos para redução do ruído speckle no aplicativo ENVI 4.7 (ITT, 2009). Foi utilizado o filtro Enhanced-Lee com janela 3x3, por este apresentar melhor resultado para ressaltar as características dessas imagens.
O MDE-SRTM foi adquirido pela National Aeronautics and Space Administration (NASA) e $\mathrm{Na}$ tional Imagery and Mapping Agency (NIMA) e gerou dados topográficos digitais para $80 \%$ da área terrestre do planeta, entre as latitudes $60^{\circ} \mathrm{N}$ e $56^{\circ} \mathrm{S}$ (IBANEZ, 2006). Esses dados foram adquiridos a bordo do ônibus espacial Endeavour, entre 11 a 22 de fevereiro de 2000, em órbita de $233 \mathrm{~km}$ de altitude e inclinação de $57^{\circ}$. O datum e o elipsóide de referência foram o WGS - 84, com dados de z em metros inteiros (RABUS et al., 2003; NASA, 2013). Os dados topográficos utilizados foram os reamostrados para $30 \mathrm{~m}$, obtidos gratuitamente do TOPODATA no endereço eletrônico < http://www.dsr. inpe.br/topodata/>. As quadrículas do MDE-SRTM foram mosaicadas com a utilização do aplicativo ENVI 4.7 (ITT, 2009). Após isto, foi feita classificação de diferentes cotas altimétricas, que permitiram salientar as morfologias de interesse para este estudo. Conjuntos de valores de elevação foram delimitados utilizando-se paletas de cores e tons de cinza, que foram personalizadas dentro do aplicativo Global Mapper. Este procedimento, embora simples, foi eficiente para auxiliar no mapeamento de algumas classes morfológicas descritas para o delta do rio Doce.

O programa Landsat da National Aeronautics and Space Administration (NASA) contou com sete sensores, sendo os mais difundidos deles o Thematic Mapper (TM), a bordo do satélite Landsat 5, e o Enhanced Thematic Mapper Plus (ETM+), a bordo do Landsat 7. Esses satélites foram lançados em 1984 e 1999, respectivamente, em uma órbita polar circular heliossíncrona com altitude de $705 \mathrm{~km}$ e inclinação de $98,20^{\circ}$ e $98,30^{\circ}$ (NOVO, 2010). Os sensores TM e $\mathrm{ETM}^{+}$possuem resolução espacial entre 15 e $120 \mathrm{~m}$, de acordo com a banda espectral, e resolução temporal de 16 dias (EMBRAPA, 2013). Para o mapeamento da rede de drenagem atual foi utilizado o mosaico de imagens TM/Landsat do dia 11 de abril de 2006. As imagens foram obtidas dos catálogos do Serviço Geológico Americano (USGS, 2013) e do Instituto Nacional de Pesquisas Espaciais (INPE, 2013). As primeiras já estavam ortorretificadas e apresentavam nível de correção 1 (L1T). Elas serviram de base para o georreferenciamento das cenas obtidas do INPE, correspondentes às órbita/ponto 215/73 e 215/74 do dia 14 de novembro de 1992. O georreferenciamento feito com o aplicativo 
TerraPixel 1.04 permitiu erros médios quadráticos inferiores a 0,5 pixels. Após esse procedimento, foi feito o mosaico das imagens utilizando o aplicativo ENVI 4.7 (ITT, 2009). As imagens foram então processadas utilizando-se diferentes composições de bandas, sendo a composição falsa-cor R4 G7 B2 a mais adequada para distinguir as classes de interesse. A análise de imagens óticas foi complementada com dados de alta resolução do Google Earth ${ }^{\mathrm{TM}}$. Estas incluíram imagens GeoEye, RapidEye, Quickbird e SPOT, de resolução espacial oscilando entre 0,5 e $10 \mathrm{~m}$.

O mapeamento das classes geomorfológicas foi realizado com base na análise visual do conjunto de dados de sensoriamento remoto utilizando a chave de interpretação apresentada na Tabela 1. Esta chave teve por objetivo diminuir a subjetividade do processo de extração das informações. Os elementos empregados na construção das chaves de interpretação estão sujeitos à resolução espectral, espacial e temporal das imagens disponíveis (NOVO, 2010). Vários elementos, como tom, textura, padrão, forma, tamanho e contexto, auxiliaram na interpretação visual das classes.

\section{Resultados}

O delta do rio Doce possui interpretação complexa, com riqueza de detalhes morfológicos que revelaram uma variedade de subambientes deposicionais, além de alternâncias de fases deposicionais e erosivas. Seis classes geomorfológicas foram distinguidas e relacionadas (Figura 3) com a drenagem atual, além dos seguintes ambientes deposicionais: cordão litorâneo/spit, paleocanal; planície interdistributária e flúvio-estuarino/ lagunar/marinho raso. Adicionalmente, houve a identificação da classe terraço fluvial na parte interna do sistema fluvial do rio Doce.

\section{Classe drenagem atual}

A classe drenagem atual, por apresentar baixa densidade, foi extraída integralmente da imagem TM/ Landsat com composição R4 G7 B2 (Figura 4A,B). Os corpos d'água apresentam baixa resposta espectral, configurando tons escuros na imagem utilizada, exceto o rio Doce, que apresenta cor azul claro. Este foi o corpo d'água permanente de maior destaque na área de estudo, sendo o responsável pela progradação do

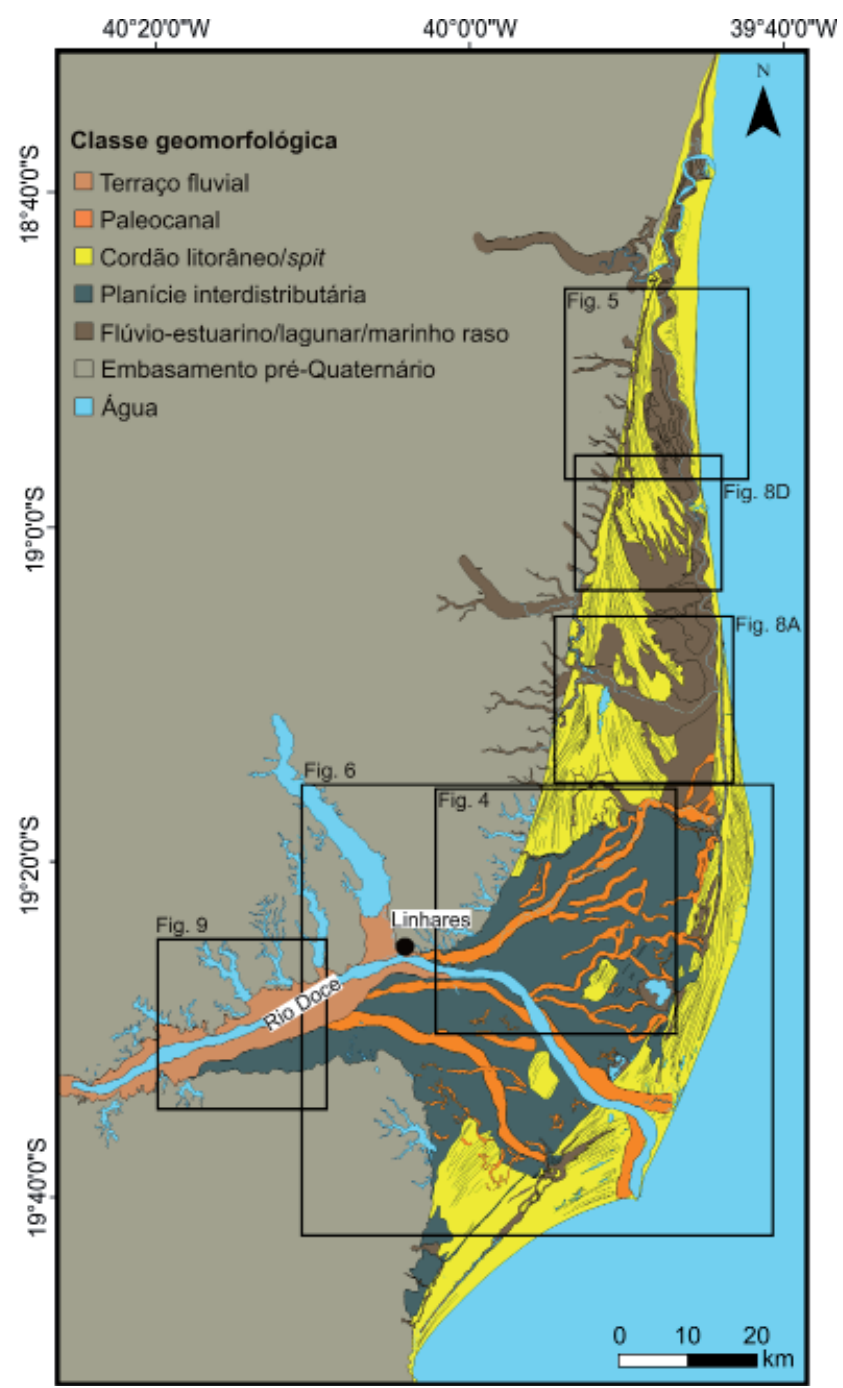

Figura 3 - Mapa geomorfológico do delta do rio Doce.

delta. Além disso, canais fluviais de dimensões menores e inúmeras lagoas se distribuem ao longo de toda a morfologia deltaica. As lagoas foram identificadas com facilidade nos produtos de sensoriamento remoto pela sua geometria circular ou alongada. Neste último caso, elas ocorrem sob a forma de uma série de feições confinadas à paleolinha de costa (Figura 4B), e claramente podem ser relacionadas a antigos sistemas estuarinos que tiveram suas desembocaduras bloqueadas durante a progradação deltaica.

\section{Classe cordão litorâneo/spit}

A classe cordão litorâneo/spit foi melhor evidenciada em imagens PALSAR (RHH GHV BHH) e TM/ Landsat (R4 G7 B2). No primeiro produto, essa classe 
Tabela 1 - Chave de interpretação desenvolvida para elaboração do mapa geomorfológico.

\begin{tabular}{|c|c|c|c|c|c|c|}
\hline $\begin{array}{c}\text { Classes } \\
\text { /Característica } \\
\text { da imagem }\end{array}$ & $\begin{array}{c}\text { Drenagem } \\
\text { atual }\end{array}$ & Paleocanal & $\begin{array}{l}\text { Terraço } \\
\text { fluvial }\end{array}$ & $\begin{array}{c}\text { Cordão } \\
\text { litorâneo/ } \\
\text { spit }\end{array}$ & $\begin{array}{c}\text { Planície } \\
\text { interdistributária }\end{array}$ & $\begin{array}{c}\text { Flúvio-estuarino/ } \\
\text { lagunar/ } \\
\text { marinho raso }\end{array}$ \\
\hline $\begin{array}{l}\text { Imagem } \\
\text { exemplo }\end{array}$ & $\begin{array}{c}\text { TM } \\
\text { R4G7B2 }\end{array}$ & $\begin{array}{c}\text { PALSAR } \\
\text { RHHGHVBHH }\end{array}$ & $\begin{array}{c}\text { PALSAR } \\
\text { RHHGHVBHH }\end{array}$ & M R4G7B2 & TM banda 5 & $\begin{array}{l}\text { PALSAR } \\
\text { RHHGHVBHH }\end{array}$ \\
\hline $\begin{array}{l}\text { Tonalidade/ } \\
\text { cor }\end{array}$ & $\begin{array}{l}\text { Azul- } \\
\text { Escuro } \\
\text { Azul- } \\
\text { claro }\end{array}$ & $\begin{array}{l}\text { Roxo } \\
\text { escuro }\end{array}$ & $\begin{array}{l}\text { Roxo com } \\
\text { limite } \\
\text { verde } \\
\text { claro }\end{array}$ & $\begin{array}{c}\text { Verde } \\
\text { Verde claro }\end{array}$ & $\begin{array}{l}\text { Preto } \\
\text { Cinza }\end{array}$ & $\begin{array}{c}\text { Roxo claro } \\
\text { Verde }\end{array}$ \\
\hline Textura & Lisa & Lisa & $\begin{array}{c}\text { Lisa/Rugo } \\
\text { sa }\end{array}$ & Lisa & Rugosa & Lisa/Rugosa \\
\hline Padrão & Irregular & Distributário & Dissecado & - & Dissecado & Dissecado \\
\hline Localização & - & $\begin{array}{l}\text { Dentro da } \\
\text { planície } \\
\text { interdistri- } \\
\text { butária }\end{array}$ & $\begin{array}{c}\grave{A} \\
\text { montante } \\
\text { do rio } \\
\text { Doce }\end{array}$ & $\begin{array}{l}\text { Intercalado } \\
\text { com áreas } \\
\text { rebaixadas }\end{array}$ & $\begin{array}{l}\text { Acompanha o } \\
\text { limite dos } \\
\text { cordões } \\
\text { litorâneos/spits }\end{array}$ & $\begin{array}{c}\text { Sobre os } \\
\text { cordões } \\
\text { litorâneos/spits }\end{array}$ \\
\hline Forma & Irregular & Irregular & Irregular & Linear & Irregular & Irregular \\
\hline Tamanho & $\begin{array}{l}\text { Grandes } \\
\text { lagoas }\end{array}$ & - & - & $\begin{array}{l}\text { Extensos } \\
\text { cordões }\end{array}$ & - & - \\
\hline
\end{tabular}
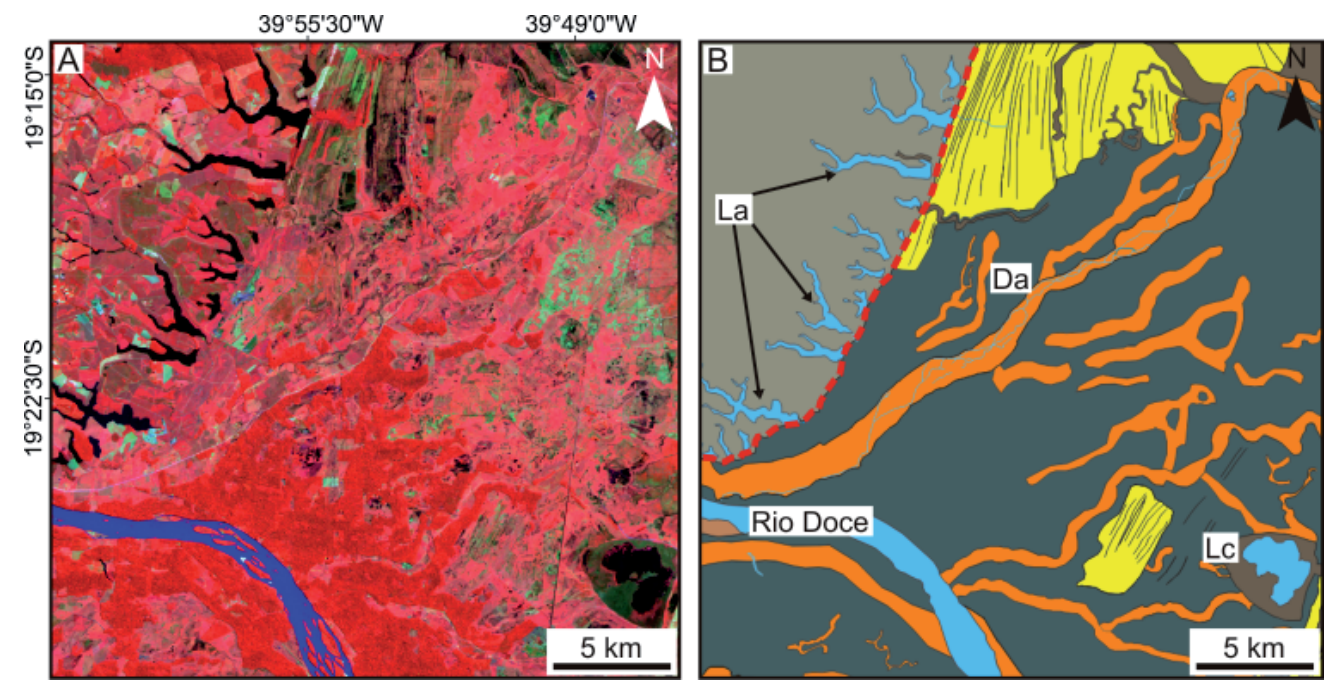

Figura 4 - A) Imagem TM/Landsat com mapa correspondente (B) ilustrando a classe drenagem atual representada pelo rio Doce, canais subsidiários (Da), lagoas circulares (Lc) e lagoas alongadas distribuidas perpendicularmente à paleolinha de costa (La). Observar que essa imagem não foi eficiente para mapear paleocanais, que foram melhor identificados nos outros produtos de sensoriamento remoto analisados (Linha tracejada em vermelho indica a paleolinha de costa; ver legenda de cores em B na Figura 3).

se caracteriza por sinal de retorno intermediário em algumas áreas e fraco em outras. Já na imagem TM/ Landsat, ela apresenta alta resposta espectral, evidenciada por tons claros. Portanto, esses dois produtos foram utilizados para o mapeamento dessa classe, que tem resposta espectral alta nas regiões de elevação topográfica sutil, e baixa nas áreas depressionadas favoráveis a acúmulo de água.

Os cordões litorâneos da área de estudo correspondem a depósitos arenosos alongados, estreitos e convexos para cima (Figura 5A-D). Em planta, eles se caracterizam por conjuntos de linhas paralelas, retilíneas a suavemente curvas e, em geral, côncavas para o mar. Essas morfologias ocorrem como sucessões paralelas 
à linha de costa. Grupos individuais são definidos por superfícies de descontinuidade que denotam períodos de erosão alternados com fases de sedimentação arenosa durante a progradação (Figura 3). Essa classe ocorre ao longo de toda a área do delta, tanto a norte, quanto a sul do rio Doce, porém sendo melhor preservada em sua porção norte. Nas proximidades do rio Doce, essa classe ocorre de forma descontínua, como feições isoladas e contornos irregulares que denotam forte erosão (Figura 3).

Entremeados aos conjuntos de cordões litorâneos da área de estudo ocorrem spits, que são reconhecidos nos produtos de sensoriamento remoto por uma série de linhas paralelas, curvas e semi-circulares, distribuídas perpendicularmente aos cordões litorâneos e, portanto, à linha de costa (Figura 5E-G; ver também setas vermelhas na Figuras 5D). Muitos dos spits registrados no delta do rio Doce estão associados com morfologias alongadas representativas de lagunas, algumas ainda não completamente abandonadas. Optou-se por não separar os spits em uma categoria à parte, dada sua ocorrência restrita na área sob forma de depósitos descontínuos e estreitos, que sistematicamente se intercalam aos cordões litorâneos.

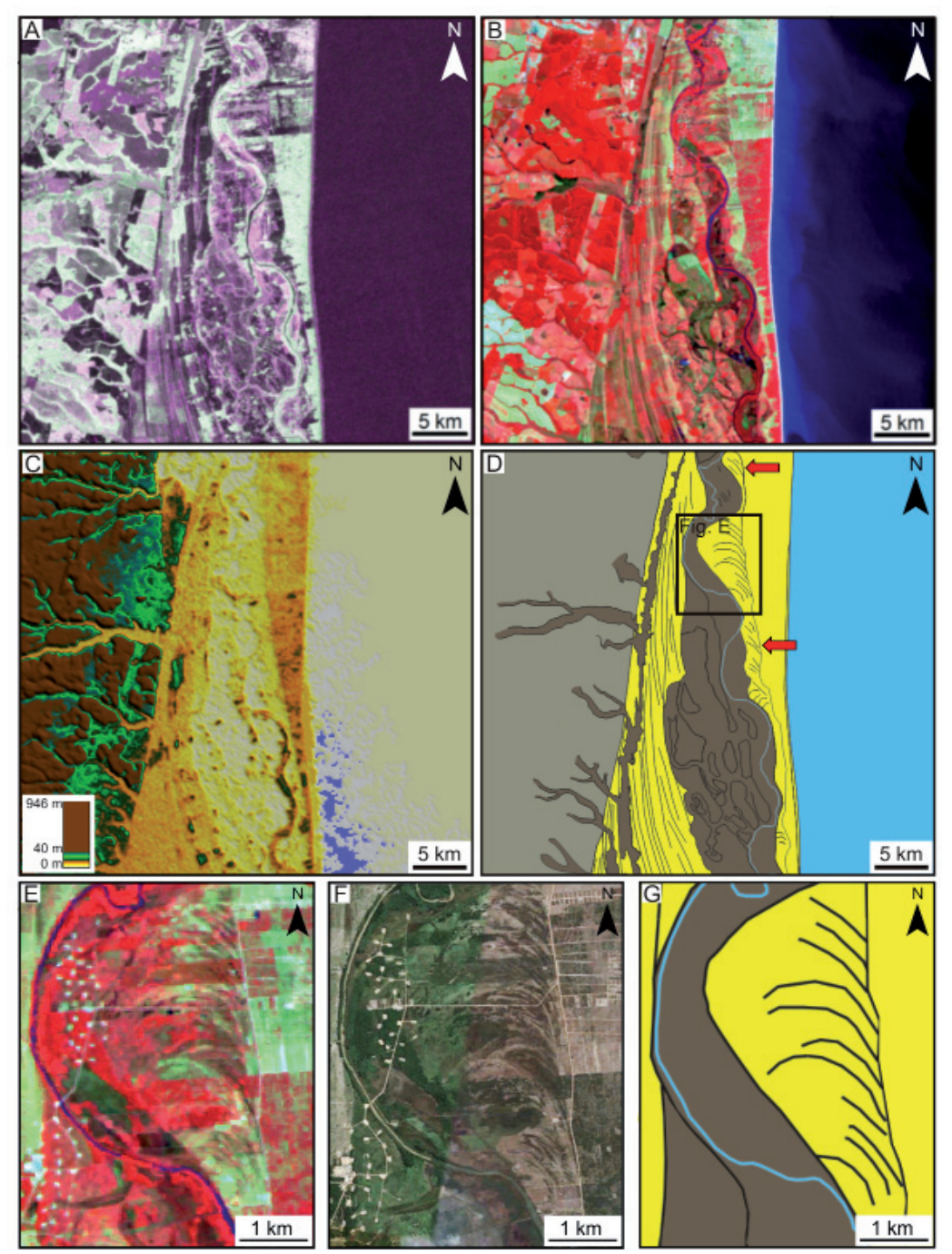

Figura 5 - Classe cordão litorâneo/spit comparada nos diferentes produtos de sensoriamento remoto analisados. A-D) Vista de cordões litorâneos em imagem PALSAR (A), Landsat (B) e MDE-SRTM (C), com o mapa geomorfológico correspondente (ver localização e legenda de cores de D na Figura 3; setas vermelhas em $D=$ depósitos de spit). E-G) Detalhes de depósito de spit (ver localização em $D$ e legenda de cores de G na Figura 3). Observar que a classe cordão litorâneo/spit é mais facilmente detectável nas imagens PALSAR e Landsat do que no MDE-SRTM. Notar, também, linhas côncavas paralelas e semi-circulares paralelas e perpendiculares à costa nos depósitos de cordões litorâneos e spits, respectivamente. 


\section{Classe paleocanal}

Esta classe foi identificada em todos os produtos de sensoriamento remoto analisados. O PALSAR (composição RHH GHV BHH) foi o mais eficaz na visualização dessa classe, que se concentra na porção central do delta no entorno do rio Doce (Figura 6). Os paleocanais relacionados com cursos anteriores do rio Doce são reconhecidos por três cinturões alongados e levemente sinuosos (ver números 1 a 3 na Figura 6), de dimensões, em geral, similares às do curso atual desse rio, ou seja, com larguras aproximadas de 1,3 km e comprimentos máximos de $50 \mathrm{~km}$ ao longo da planície deltaica. Esses paleocanais ocorrem ora a sul ora a norte do rio Doce atual. Além desses, uma rede de paleocanais menores e de padrão distributário ocorre principalmente a norte do rio Doce atual (ver Cd na Figura 6), embora sejam também observados, em menor frequência, a sul desse rio.

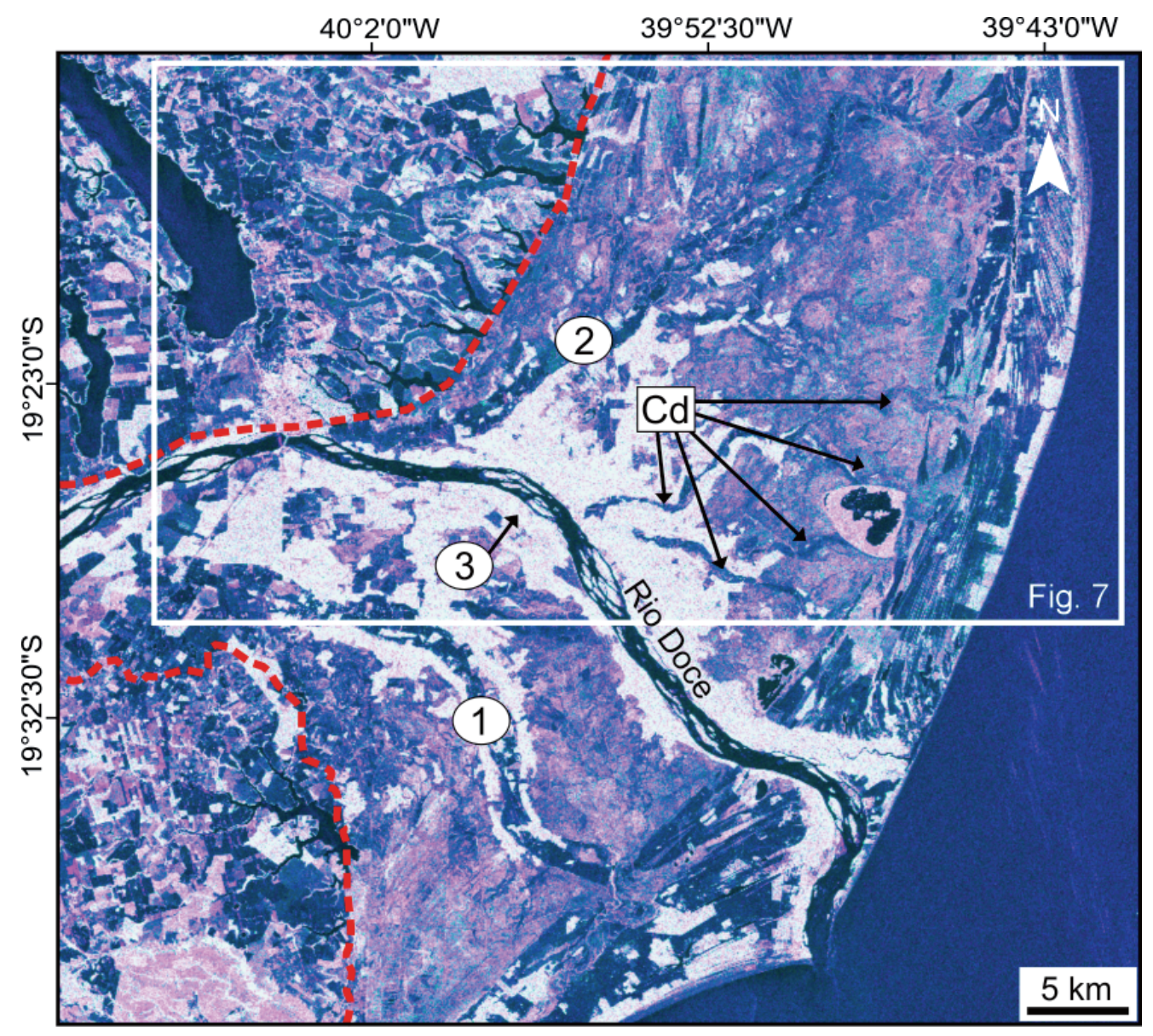

Figura 6 - Classe paleocanal vista em imagem PALSAR (ver localização na Figura 3; linha vermelha tracejada=paleolinha de costa). Observar os três paleocanais (1 a 3) de dimensões similares ao curso do rio Doce atual, que são interpretados como representativos de cursos pretéritos. Notar, ainda, uma série de canais distributários menores (Cd) entre o rio Doce atual e o paleocanal 2.

\section{Classe planície interdistributária}

A classe planície interdistributária (Figura 7) foi melhor identificada em imagens PALSAR (Figura 7A), tendo também sido a única mapeada sobre a banda 5 do TM/Landsat (Figura 7B). Nesta última, essa classe ocorre em tons escuros, o que se associou à natureza argilosa e, possivelmente, úmida do substrato. A classe planície interdistributária foi registrada na parte central do delta (Figura 3). Ela foi reconhecida pela íntima associação com a classe de paleocanais, ocorrendo em suas margens e nos interflúvios, como é típico desses ambientes da planície deltaica. 


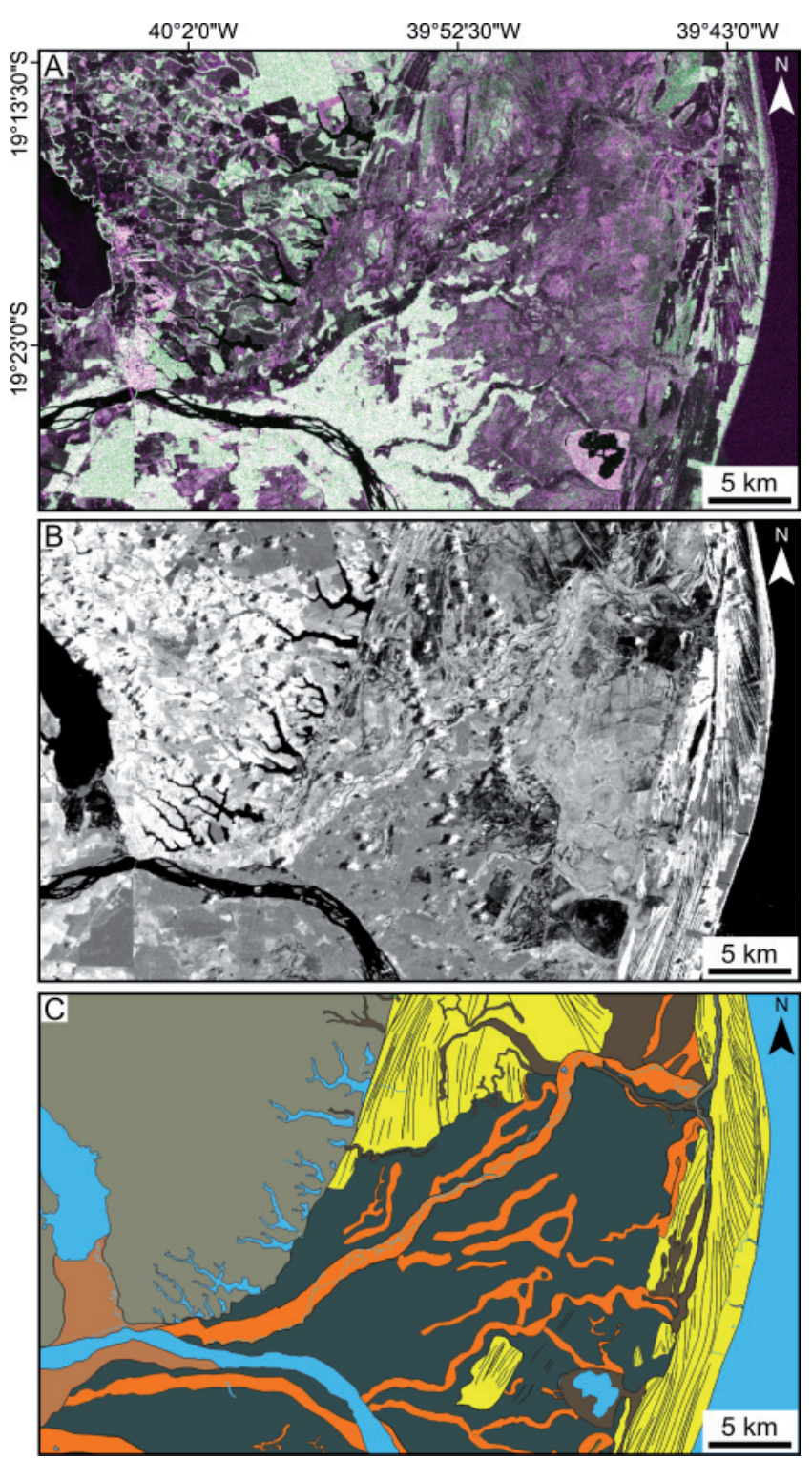

Figura 7 - Classe planicie interdistributária vista em imagens PALSAR (A) e TM/Landsat (B), banda 5, com mapa geomorfológico correspondente $(C)$ (ver localização na Figura 6 e legenda de cores de C na Figura 3).

\section{Classe flúvio-estuarino/lagunar/marinho raso}

A classe flúvio-estuarino/lagunar/marinho raso foi principalmente reconhecida em imagens PALSAR (RHH GHV BHH) e, secundariamente em imagem TM/Landsat (R4 G7 B2) (Figura 8A,B). Além desses produtos, imagens disponíveis no Google Earth ${ }^{\mathrm{TM}}$ foram utilizadas para o mapeamento de detalhe dessa classe. $\mathrm{Na}$ imagem PALSAR, essa classe apresentou resposta espectral tanto em tons claros como escuros. Essa classe se distribui predominantemente a norte do rio Doce, com início a aproximadamente $35 \mathrm{~km}$ deste, onde forma um cinturão alongado na direção norte-sul que se interdigita com a classe cordão litorâneo/spit (Figura 3). Embora ocorra em proximidade com esta, a classe flúvio-estuarino/lagunar/marinho raso foi passível de separação dado o contato tipicamente brusco e erosivo com aquela, o que claramente denota a interrupção do processo de progradação do delta (Figura 8D,E). Além disto, sua superfície é de textura lisa, diferentemente da superfície dos cordões litorâneos/spits, que se caracterizam por séries de linhas paralelas entre si. A classe flúvio-estuarino/lagunar/marinho raso consiste em cinturões alongados e sinuosos que se distribuem paralelamente ou perpendicularmente à linha de costa $\mathrm{e}$ da paleocosta. Esses cinturões são localmente alargados e ou afunilados (Figura 3). Salienta-se, ainda uma série desses cordões afunilados distribuídos perpendicularmente à paleolinha de costa na porção centro norte da planície deltaica (ver setas na Figura 3), sendo eles de geometria similar à série de lagoas alongadas que ocorrem margeando a paleolinha de costa na porção central do delta.

\section{Classe terraço fluvial}

A classe terraço fluvial foi reconhecida principalmente com base na imagem PALSAR (RHH GHV BHH) (Figura 9). Similarmente à classe descrita anteriormente, a resposta espectral dessa classe também variou na imagem de radar entre tons claros e escuros. No sistema progradante do rio Doce, a classe terraço fluvial está restrita à porção mais interior, à montante do rio Doce, onde forma dois cinturões alongados em ambas as margens desse rio. Estes terraços têm aproximadamente $40 \mathrm{~km}$ de extensão e até $10 \mathrm{~km}$ de largura.

\section{Discussão}

A integração de dados multissensores foi eficiente na identificação e caracterização das morfologias do delta do rio Doce. As diferentes propriedades dos sensores, bem como das bandas utilizadas, forneceram dados complementares para a melhor visualização das morfologias constituintes desse sistema deposicional. O mapa geomorfológico produzido pode ser usado para 
Caracterização Morfológica do Delta do Rio Doce (ES) com Base em Análise Multissensor
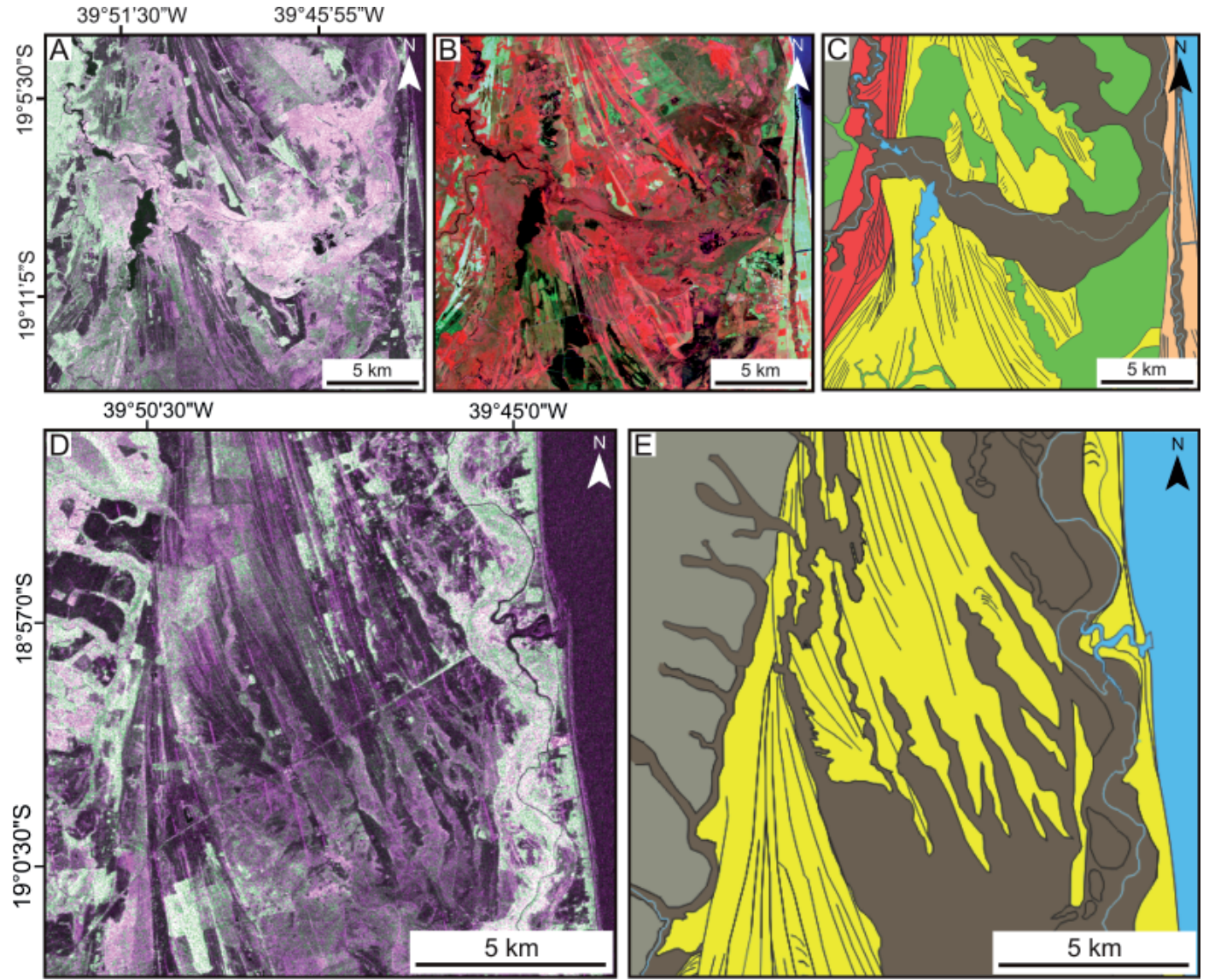

Figura 8-Classe flúvio-estuarino/lagunar/marinho raso. A-C) Visualização em imagens PALSAR (A); TM/Landsat (B); Mapa geomorfológico correspondente (C). D-E) Visualização dessa classe em imagem PALSAR (D) e mapa geomorfológico correspondente (E), ilustrando seu contato brusco e erosivo com a classe cordão litorâneo/spit. Ver localização das Figuras e legenda de C e E na Figura 3.
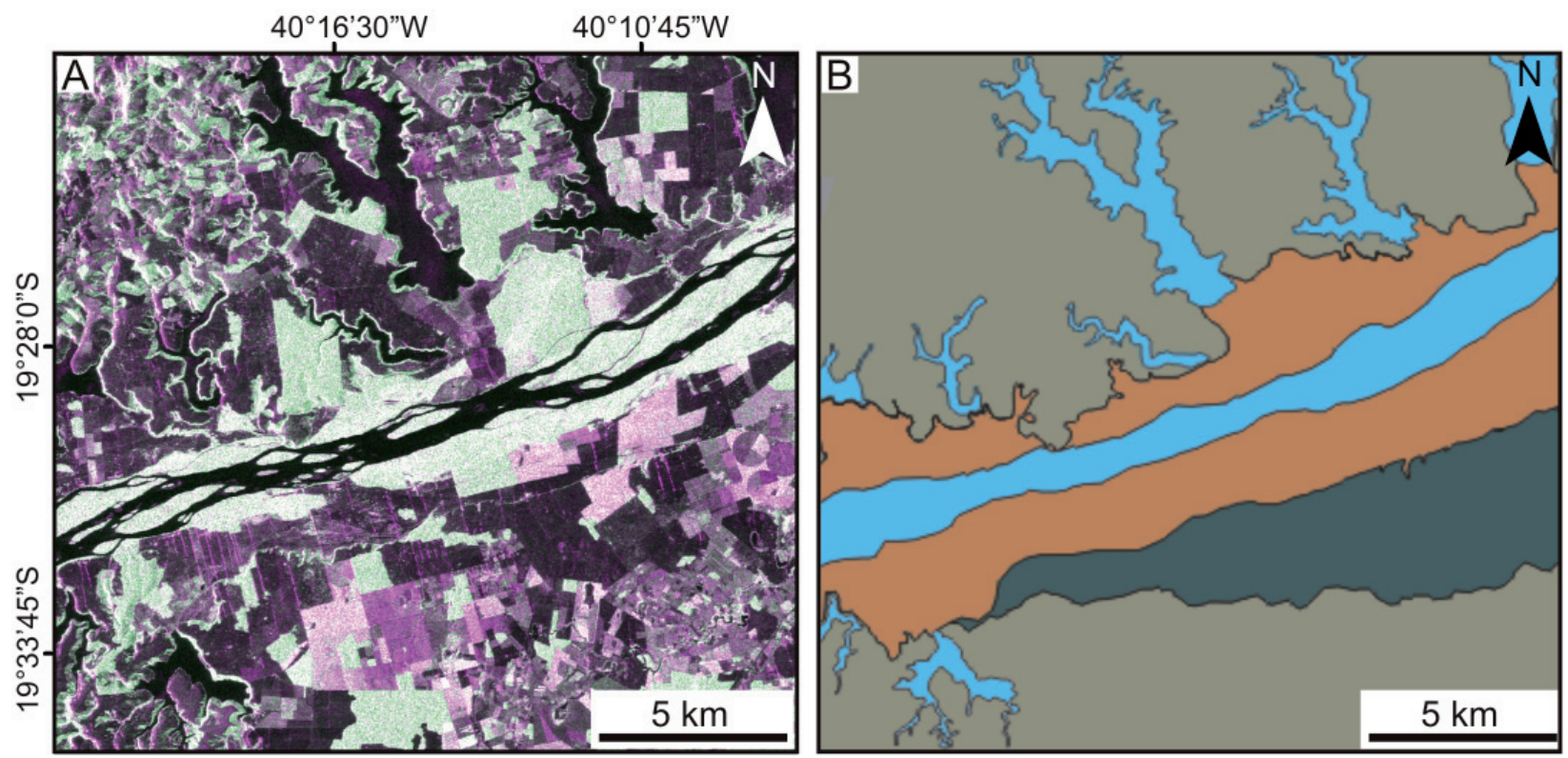

Figura 9 - Comparação entre os diferentes produtos analisados no mapeamento de terraços fluviais: A - PALSAR com composição RHH GHV BHH; B - Mapa morfológico correspondente (ver localização de A,B e legenda de cores da Figura B na Figura 3). 
se fazer considerações preliminares complementares a respeito da dinâmica sedimentar do delta do rio Doce.

\section{Avaliação dos produtos de sensoriamento remoto}

$\mathrm{O}$ uso de paletas com fatiamento dos valores de elevação a partir do MDE-SRTM gerou imagens que serviram para realçar principalmente parte das morfologias de paleocanais correspondentes a antigos cursos do rio Doce. A identificação dessa classe no MDE-SRTM ocorreu onde existem gradientes topográficos sutis. A presença de vegetação arbórea sobre os paleocanais contribuiu, em alguns casos, para aumentar os valores topográficos e salientar a classe paleocanal no MDE-SRTM utilizado. Por outro lado, este produto mostrou baixa eficiência na classificação das demais morfologias da área de estudo, o que foi atribuído à variação altimétrica dominantemente baixa dessa planície deltaica.

As imagens TM/Landsat contribuíram eficientemente para identificar a maioria das classes geomorfológicas. Em particular, a composição colorida R4 G7 B2 apresentou os melhores resultados para a classificação visual. Isto pode ser explicado pela associação das bandas TM/Landsat selecionadas com cada um dos canais (RGB). Assim, a banda 4 é mais sensível à morfologia do terreno, prestando-se melhor ao mapeamento da rede de drenagem e da vegetação verde, densa e uniforme. A banda 7 permite a obtenção de informações sobre geomorfologia, solos e geologia, enquanto a banda 2 caracteriza-se pela boa penetrabilidade em corpos d'água (NOVO, 2010). A seleção dessas três bandas do TM/Landsat gerou uma imagem composta colorida falsa-cor que realçou as morfologias do delta do rio Doce e, em geral, permitiu sua classificação com mais facilidade relativamente aos outros produtos analisados.

Portanto, as composições utilizadas das imagens TM/Landsat facilitaram a identificação de corpos d'água, como canais e lagoas, devido à baixa resposta espectral, representada por tons escuros característicos do objeto água. Apenas o rio Doce foi caracterizado por tons de azul claro, provavelmente devido à presença de material em suspensão. Quando bem preservadas e na ausência de vegetação, a maioria das morfologias do delta foi facilmente reconhecida nessas imagens. O mapeamento da classe planície interdistributária foi facilitado pela análise da banda 5 da imagem TM/Landsat, representativa do período chuvoso (novembro). O bom desempenho desse produto para identificação dessa morfologia foi relacionado com as propriedades dessa banda na região do infravermelho de ondas curtas. Essa banda sofre perturbações em caso de ocorrer excesso de chuva antes da obtenção da cena pelo satélite, portanto podendo representar melhor terrenos de maior umidade (NOVO, 2010). Neste caso, tais terrenos foram relacionados a planícies interdistributárias por estas conterem elevada proporção de argilas, que tornam o substrato impermeável e, portanto, úmido na superfície. Como a imagem foi adquirida em novembro (período chuvoso para a região), a diferença de umidade entre o material argiloso da planície interdistributária e o material arenoso dos cordões litorâneos/spits favoreceu a discriminação dessas classes.

As imagens PALSAR também apresentaram bons resultados na separação das classes geomorfológicas. Essas imagens se mostraram particularmente úteis para o reconhecimento de morfologias vegetadas. $\mathrm{O}$ realce de morfologias em locais com vegetação pode ser explicado pelas características deste sensor. Assim, isto se deve à energia de micro-ondas da banda $\mathrm{L}$, que possui maior penetração no dossel, onde o espalhamento volumétrico ocasionado pela estrutura vegetal gera a despolarização da energia (HENDERSON; LEWIS, 1998). Além disso, também pode ocorrer a transmissão de inúmeros pulsos até a superfície do solo, que são expostos ao espalhamento superficial em seu limite com a vegetação (JENSEN, 2009).

As classes melhor mapeadas com base nas imagens PALSAR com composição RHH GHV BHH foram de paleocanal, terraço fluvial e flúvio-estuarino/lagunar/ marinho raso. Imagem resultante desse sensor apresentou sinal de retorno fraco para paleocanais de menores dimensões e desprovidos de cobertura vegetal. Isto pode ser explicado pela penetrabilidade máxima da banda $\mathrm{L}$ atingir apenas $10 \mathrm{~cm}$ em solo descoberto (JENSEN, 2009). Já os paleocanais de dimensões maiores, i.e., aqueles representativos de antigos cursos do rio Doce, geralmente possuem vegetação em seu entorno. Por isso, o sinal de resposta da cobertura vegetal foi alto. Esse brilho em imagens com polarização cruzada (polarização HV associada ao canal verde) resulta da maior contribuição do espalhamento volumétrico (interior do dossel) (JENSEN, 2009).

A identificação da classe terraço fluvial por sinal de retorno fraco na imagem PALSAR também pode ser explicada pelo mesmo princípio de umidade descrito anteriormente para os paleocanais de dimensões menores. 
A classe terraço fluvial, em virtude da proximidade com o rio Doce, apresenta umidade elevada e, portanto, responde com fraco sinal de retorno na imagem PALSAR, sendo reconhecida nas imagens por tonalidades escuras. Além disso, existem diversos fragmentos de vegetação na área dessa classe, que apresentam brilho associado à forte resposta espectral, explicado pela maior contribuição do espalhamento volumétrico.

Outra morfologia extraída da imagem PALSAR foi a classe flúvio-estuarino/lagunar/marinho raso. A resposta espectral variável dessa classe pelo sensor PALSAR pode ser devido ao fato dela ser constituída por sedimentos variando desde mais argilosos a mais arenosos, já que ela inclui ambientes deposicionais costeiros representativos de áreas de baixa e alta energia de fluxo. As respostas espectrais variáveis podem ter sido também influenciadas pelo tipo de cobertura do terreno, sendo áreas de tonalidades claras relacionadas com maiores ocorrências de solo exposto, quando ocorre maior penetrabilidade da banda L.

\section{Considerações preliminares sobre a dinâmica sedimentar}

A análise do mapa geomorfológico do delta do rio Doce permite algumas considerações preliminares a respeito de sua dinâmica sedimentar. Em particular, o reconhecimento de extensivos depósitos relacionados a ambientes flúvio-estuarinos/lagunares/marinho rasos se constitui em um elemento importante para sugerir que a deposição dos cordões litorâneos/spits que caracterizam o delta do rio Doce não ocorreu de forma contínua. Pelo contrário, esses cordões foram sendo adicionados ao delta de maneira episódica, sendo eles intercalados com depósitos representativos de nível relativo de mar alto. Durante essa fase, cordões litorâneos/spits previamente formados foram parcialmente erodidos. Tal processo resultou no retrabalhamento desses depósitos, registrado por suas bordas irregulares e, portanto, erosivas. O contato direto com depósitos flúvio-estuarinos/lagunares/ marinho rasos permite sugerir que a progradação deltaica foi momentaneamente interrompida, sendo substituída por fase transgressiva que atingiu toda a extensão do delta do rio Doce. Subsequentemente, houve retomada do influxo sedimentar alimentado pelo rio Doce, o que resultou na formação de novos cordões litorâneos/spits em toda porção externa do delta, processo que salientou sua morfologia cuspidada típica de delta de onda.
Uma observação importante derivada da análise do mapa geomorfológico é a caracterização da natureza instável do rio Doce. Hoje, esse rio flui ao longo da planície deltaica de oeste para leste, com inflexão para sudeste. No passado, seu curso apresentava essa mesma configuração, porém em posição mais a sul. Posteriormente, é possível que o curso do rio Doce tenha se deslocado para norte de seu curso atual, de onde retornou para uma posição mais central já próxima de seu curso atual. Esta dinâmica de evolução do canal alimentador do delta difere do padrão que se pode extrair de outros deltas de onda que ocorrem ao longo da costa leste do Brasil. Isto porque deltas como os dos rios São Francisco, Jequitinhonha e Paraíba do Sul (e.g., DOMINGUEZ et al., 1981, 1983; SUGUIO et al., 1982; MARTIN et al., 1984, 1996; DOMINGUEZ, 1987; BITTENCOURT et al., 2007) não registram, em suas superfícies, paleocanais similares aos do rio Doce. Essa comparação leva a sugerir que, apesar da similaridade morfológica, a evolução do delta do rio Doce pode ter sido mais complexa que desses outros deltas. Causas ligadas com fatores intrínsecos aos processos sedimentares, bem como a outros possíveis fatores, como atividade tectônica local ou regional, podem ter afetado a evolução desse delta. Alguns trabalhos prévios já sugeriram a influência de reativações tectônicas na sedimentação quaternária desta região (e.g., HATUSHIKA, 2005; HATUSHIKA et al., 2005, 2007; MELLO et al., 1999, 2005; 2011; BRICALLI; MELLO, 2013), hipótese que deve ser melhor investigada em investigações futuras.

Outro aspecto importante que resultou da análise do mapa geomorfológico foi o registro de depósitos relacionados à planície interdistributária em uma ampla região da parte central do delta. Esses depósitos, que ocorrem associados a uma variedade de paleocanais, tanto representativos de cursos pretéritos do rio Doce, como de uma malha de canais distributários subsidiários, registram ambientes de baixa energia formados marginalmente aos canais durante sua evolução. A migração sucessiva desses canais, registrada por uma abundância de paleocanais, e o acúmulo de sedimentos em suas margens, contribuíram para produzir uma alta proporção desses depósitos na parte central da planície deltaica. Além disso, a migração de canais e de suas planícies interdistributárias associadas resultou em forte erosão dos cordões litorâneos/spits. Com isso, a 
maioria desses depósitos formados próximos aos canais alimentadores foi erodida ou recoberta pelos depósitos da planície interdistributária. Atualmente, restam apenas algumas ilhas que servem para documentar que, no passado, cordões litorâneos/spits ocorriam em toda a extensão da planície deltaica, incluindo sua porção central, agora ocupada, em grande parte, pelos depósitos da planície interdistributária. Tendo em vista esse registro, pode-se hipotetizar que o delta do rio Doce pode ter evoluído, desde seus estágios iniciais, como um delta de onda que progradou em mar aberto, e não como delta intralagunar, como proposto previamente na literatura.

\section{Conclusões e considerações finais}

O emprego de produtos de sensoriamento remoto e da análise multissensor foi eficiente na caracterização do delta do rio Doce. As imagens óticas e de radar auxiliaram na identificação das morfologias recentes e passadas, sendo as últimas melhor registradas em imagens de radar. As características das imagens geradas pelo sensor ativo, como ausência de nuvens e interação da banda L, foram de suma importância nas análises preliminares e serviram de base para iniciar o reconhecimento das classes geomorfológicas. O MDE-SRTM foi útil apenas na identificação dos paleocanais representativos de antigos cursos do rio Doce.

A caracterização morfológica do delta do rio Doce apresentada nesse trabalho contribuiu para melhorar a reconstituição de seus vários subambientes, bem como discutir, ainda que de forma preliminar, a sucessão de processos deposicionais e erosivos que levaram à sua evolução. Sugere-se, com base nos dados obtidos, que o delta do rio Doce teve evolução mais complexa que os demais deltas de onda que ocorrem na costa leste do Brasil. O forte deslocamento do rio Doce, bem como de distributários menores a ele associados, resultou em vários paleocanais ao longo da parte central da planície deltaica. Além disso, uma proporção elevada de depósitos de planície interdistributária nessa região do delta registra intenso retrabalhamento de depósitos de cordões litorâneos/spits previamente formados durante a progradação deltaica. Fases progradacionais se alternaram com fases transgressivas, as últimas bem registradas pela presença de extensos depósitos relacionados a ambientes flúvio-estuarinos/lagunares/marinho rasos. O delta do rio Doce pode ter se caracterizado como um delta de onda formado em mar aberto desde seus estágios ini- ciais. Isto é sugerido com base na ocorrência de ilhas de cordões litorâneos/spits em suas porções centrais, onde estudos prévios hipotetizaram a ocorrência de possível laguna. Estudos futuros integrando o mapa geomorfológico aqui apresentado com informações geológicas e cronológicas são recomendados para se testar essa nova hipótese e reconstituir a história evolutiva do delta do rio Doce de forma mais precisa.

\section{Referências}

AGÊNCIA NACIONAL DO PETRÓLEO, GÁS NATURAL E BIOCOMBUSTÍVEIS (ANP). Nona Rodada de Licitações

Bacia do Espírito Santo. Disponível em: $<\mathrm{http}: / / \mathrm{www}$.brasilbounds.gov.br/arquivos/Seminario_Tecnico_R9/Espirito_ Santo(portugues).pdf $>$. Acesso em: 24 mar. 2014.

BITTENCOURT, A. C. S. P.; Dominguez, J. M.; Martin, L.; Silva, I. R.; De-Medeiros, K. O. Past and current sediment dispersion pattern estimates through numerical modeling of wave climate: an example of the Holocene delta of the Doce River, Espírito Santo, Brazil. Anais da Academia Brasileira de Ciências, v. 79, n. 2, p. 333-41. Disponível em: http://www. ncbi.nlm.nih.gov/pubmed/17625686, 2007.

BRICALLI, L. L.; MELLO, C. L. Padrões de lineamentos relacionados a litoestrutura e fraturamento neotectônico (Estado do Espírito Santo, SE do Brasil). Revista Brasileira de Geomorfologia, v. 14, n. 3, 2013.

DOMINGUEZ, J. M. L.; BITTENCOURT, A. C. S. P.; MARTIN, L. Esquema evolutivo da sedimentação quaternária nas feições deltaicas dos rios São Francisco (SE/AL), Jequitinhonha (BA), Doce (ES) e Paraíba do Sul (RJ). Revista Brasileira de Geociências, v. 11, n. 4, p. 227-237, 1981.

DOMINGUEZ, J. M. L.; BITTENCOURT, A. C. S. P.; MARTIN, L. Papel da deriva litorânea de sedimentos arenosos na construção das planícies costeiras associadas às desembocaduras dos rios São Francisco (SE-AL), Jequitinhonha (BA) e Paraíba do Sul (RJ). Revista Brasileira de Geociências, v. 13, n. 2, p. 98-105, 1983.

DOMINGUEZ, J.M.L. Quaternary Sea-Level Changes and the Depositional Architecture of Beach-Ridge Strandplains Along the Coast of Brazil. Tese de Doutorado. Universidade de Miami, Estados Unidos, 1987, 288p.

DOMINGUEZ, J. M. L.; MARTIN, L.; BITTENCOURT, A. C. S. P. Sea-level history and Quaternary evolution of river mouth-associated beach-ridge plains along the east-southeast Brazilian coast: a summary. In: NUMMEDAL, D.; PILKEY, O. 
H.; HOWARDS, J. D. (Eds) Sea-level fluctuation and coastal evolution, Special Publication of the Society of Economic Paleontologists and Mineralogists, v. 41, p. 115-127, 1987.

EMPRESA BRASILEIRA DE PESQUISA AGROPECUÁRIA (EMBRAPA) Satélites de Monitoramento, 2013. Disponível em: <http://www.sat.cnpm.embrapa.br/>. Acesso em: 10 abr. 2013.

HATUSHIKA, R. S. Investigação Sismoestratigráfica do Lago Juparanã - Baixo Curso do Rio Doce, Linhares (ES). Monografia (Graduação em Geologia) - Instituto de Geociências, Universidade Federal do Rio de Janeiro, Rio de Janeiro, 2005, $84 \mathrm{p}$.

HATUSHIKA R. S.; MELLO, C. 1.; SILVA, C.G. Evidências de atuação neotectônica na formação do lago JuparanãLinhares (ES). In: Associação Brasileira de Estudos do Quaternário (ABEQUA), 10, Guarapari, 2005. Resumos expandidos, Guarapari, CD-ROM, 2005.

HATUShiKA, R. S.; Silva, C. G.; MELlO, C. L. Sismoestratigrafia de alta resolução no Lago Juparanã, Linhares (Es Brasil) como base para estudos sobre a sedimentação e

tectônica quaternária. Revista Brasileira de Geofísica , v. 25, p. 433-442, 2007.

HENDERSON, F. M.; LEWIS, A. J. Principles and applications of imaging radar: manual of remote sensing. New York: John Wiley \& Sons, 1998. 896p.

IBANEZ, D. M. Integração de dados de sensoriamento remoto (SRTM e RADARSAT-1), geologia, gravimetria e magnetometria para estudo morfoestrutural da área do Rio Uatumã, Bacia do Amazonas. Dissertação de Mestrado, Instituto Nacional de Pesquisas Espaciais (INPE), 2006, 161p.

INSTITUTO BRASILEIRO DE GEOGRAFIA E ESTATÍSTICA (IBGE). Levantamento de Recursos Naturais, vol. 34. MMEFolhas SF 24, Rio Doce, 1987.

INSTITUTO NACIONAL DE PESQUISAS ESPACIAIS (INPE). Catálogo de imagens, 2013. Disponível em: <http:// www.dgi.inpe.br/CDSR/>. Acesso em: 10 out. 2012.

ITT Visual Information Solution. ENVI 4.7. version 4.7. Boulder, Colorado, EUA, 2009.

JAXA - Japan Aerospace Exploration Agency. ALOS Research and Application Project . EORC, JAXA, 2007. Disponível em: <http://www.eorc.jaxa.jp/ALOS/en/about/.htm>. Acesso em: 04 abr. 2013.

JENSEN, J. R. Sensoriamento Remoto do Ambiente: uma perspectiva em recursos terrestres. 2. ed. São José dos Campos:
Parêntese, 2009. 598p.

KÖPPEN, W. Climatologia: con un estudio de los climas de la tierra. Fondo de Cultura Econômica. México. 1948. 479p.

MARTIN, L.; SUGUIO, K.; FLEXOR, J. M.; DOMINGUEZ, J. M. L.; AZEVEDO, A. D. Evolução da planície costeira do rio Paraíba do Sul (RJ) durante o quaternário: influência das flutuações do nível do mar. Anais do XXXIII Congresso Brasileiro de Geologia. Anais... p.14. Rio de Janeiro, 1984.

MARTIN, L.; SUGUIO, K.; FLEXOR, J. M.; ARCHANJO, J. L. Coastal Quaternary Formations of the Southern Part of the State of Espírito Santo (Brazil). Anais da Academia Brasileira de Ciências, v. 68, n. 3, p. 389 - 404, 1996.

MELLO, C. L; METELO, C. M. S.; SUGUIO, K.; KOHLER, H. C. Quaternary sedimentation, neotectonics and the evolution of the Doce River middle valley lake system (Southeastern Brazil). Revista do Instituto Geológico, v. 20(1/2), p. 29-36, 1999.

MELLO, C. L.; RODRIGUES, H. B.; HATUSHIKA, R. S. Reativações tectônicas cenozóicas na Faixa de Lineamentos Colatina (ES). In: Simpósio Nacional de Estudos Tectônicos/ IV International Symposium on Tectonics of the Brazilian Geological Society, 10., Curitiba. Anais... Curitiba: SBG, p. 186-188, 2005.

MELlO, C. L., SANTOS, F. F. V., HATUSHIKA, R. S., SILVA, C. G.; OLIVEIRA, P. E. de. Considerações a respeito da idade do sistema de lagos do baixo curso do rio Doce (Linhares, ES). In: XIII Congresso da Associação Brasileira de Estudos do Quaternário ABEQUA, III Encontro do Quaternário Sulamericano, XIII ABEQUA Congress - The South American Quaternary: Challenges and Perspectives, 2011.

MILANI, E. J.; BRANDÃO, J. A. S. L.; ZALÁN, P. V.; GAMBOA, L. A. P. Petróleo na margem continental brasileira: geologia, exploração, resultados e perspectivas. Revista Brasileira de Geofísica, v. 18, n. 3, p. 1-46, 2001.

MOHRIAK, W. U. Bacias Sedimentares da Margem Continental Brasileira. In: Geologia, Tectônica e Recursos Minerais do Brasil. Brasília: CPRM, p. 87-94, 2003.

NASA. Jet Propulsion Laboratory. SRTM: Shuttle Radar Topography Mission.California, 2006. Disponível em: <http:// www2.jpl.nasa.gov/srtm/>. Acesso em: 21 jan. 2013.

NOVO, E. M. L. de M. Sensoriamento remoto: princípios e aplicações. São Paulo: Blucher, $4^{\mathrm{a}}$ Edição revista e ampliada, 2010. 367p.

RABUS, B.; EINEDER, M.; ROTH, A.; BAMLER, R. The Shuttle Radar Topography Mission - a new class of digital 
elevation models acquired by spaceborne radar. ISPRS Journal of Photogrammetry \& Remote Sensing, v. 57, p. 241-262, 2003.

RESTREPO, J. D.; LÓPEZ, S. A. Morphodynamics of the Pacific and Caribbean deltas of Colombia, South America. Journal of South American Earth Sciences, v. 25, n. 1, p. 1-21. doi: 10.1016/j.jsames.2007.09.002, 2008.

RoSEnQVist, M. S.; WATANABE, M. AlOS PALSAR: Technical outline and mission concepts, 4th International Symposium on Retrieval of Bio- and Geophysical Parameters from SAR Data for Land Applications, p. 1-7, 2004.

SHIMADA, M.; ISOGUCHI, O.; TADONO, T.; ISONO, K. PALSAR radiometric and geometric calibration.Geoscience and Remote Sensing, IEEE Transactions on, v. 47, n. 12, p. 3915-3932, 2009.

SOUZAFILHO, P. W. M.; PARADELLA, W. R. Use of synthetic aperture radar for recognition of Coastal Geomorphological Features, land-use assessment and shoreline changes in Bragança coast, Pará, Northern Brazil. Anais da Academia Brasileira de Ciências, v. 75, n. 3, p. 341-356, 2003.

SUGUIO, K.; MARTIN, L. Significance of Quaternary sea-level fluctuations for delta construction along the Brazilian Coast. Geo-Marine Letters, v.1, p. 181-185, 1981.
SUGUIO, K.; MARTIN, L.; DOMINGUEZ, J. M. L. Evolução da planície costeira do rio Doce (ES) durante o quaternário: influência das flutuações do nível do mar. IV Simpósio do Quaternário no Brasil. Anais... p. 93-116, 1982.

TEIXEIRA, S. G.; SOUZA FILHO, P. W. M. Mapeamento de ambientes costeiros tropicais (Golfão maranhense, Brasil) utilizando imagens de sensores remotos orbitais. Revista Brasileira de Geofísica, v. 27, p. 69-82, 2009.

UNITED STATES GEOLOGICAL SURVEY (USGS). Catálogo de imagens, EROS (Earth Resources Observation and Science Center). 2013. Disponível em: <http://glovis.usgs.gov/>. Acesso em: 14 set. 2012.

VALERIANO, M. M.; KUPLICH, T. M.; STORINO, M.; AMARAL, B. D.; MENDES JR, J. N.; LIMA, D. J. Modeling small watersheds in Brazilian Amazonia with shuttle radar topographic mission-90m data. Computers \& Geosciences, v. 32, n. 8, p. 1169-1181, 2006.

VALERIANO, M. M.; ROSSETTI, D. F. TOPODATA: seleção de coeficientes geoestatísticos para o refinamento unificado de dados SRTM. São José dos Campos: INPE, 2010. 74 p. (sid. inpe.br/mtc-m19@80/2010/05.10.18.35-RPQ). Disponível em: <http://urlib.net/8JMKD3MGP7W/37FCGLP>. Acesso em: jan 2013. 